\title{
The first reported outbreak of equine herpesvirus myeloencephalopathy in New Zealand
}

\author{
AMJ McFadden*» ${ }^{\S}$ D Hanlon ${ }^{\dagger}$, RK McKenzie ${ }^{\dagger}$, I Gibson ${ }^{\ddagger}$, IM Bueno*, DJ Pulford*, D \\ Orr*, M Dunowska*, WL Stanislawek*, RP Spence*, WL McDonald*, G Munro*, IG \\ Mayhew
}

\footnotetext{
* Ministry for Primary Industries, 66 Ward St, Wallaceville, Upper Hutt, New Zealand

† Matamata Veterinary Services Ltd, 26 Tainui Street, Matamata, New Zealand

$\ddagger$ New Zealand Veterinary Pathology, Hamilton, New Zealand

\# Institute of Veterinary, Animal and Biomedical Sciences, Massey University, Palmerston North, New Zealand

\Corresponding Author: E-mail: Andrew.McFadden@mpi.govt.nz
}

\section{Supplementary Information 1. Laboratory methods used in the investigation of the first reported outbreak of equine herpesvirus myeloencephalopathy (EHM) in New Zealand}

\section{Molecular analysis}

Samples collected early in the outbreak investigation included nasal swab fluids, CSF fluids, and blood in EDTA. Buffy coat (white cell) preparations from whole blood were collected from the interface between plasma and the red blood cell pellet after centrifugation at $2000 \mathrm{x} g$ for 20 minutes. Fresh tissues obtained at post-mortem were homogenized as $10 \% \mathrm{w} / \mathrm{v}$ suspensions into modified virus transport media (x1 MEM + Earles Salts, 0.16\% v/v amphotericin B, 0.03\% gentamycin, $0.01 \%$ kanamycin, $0.02 \%$ v/v streptomycin, $1000 \mathrm{IU}$ penicillin $/ \mathrm{ml}, 0.5 \% \mathrm{BSA}, 0.1 \mathrm{M}$ Hepes buffer pH7.2; Fort Richard, Auckland, NZ), the samples were centrifuged at $1350 \times \mathrm{x}$ for 15 minutes and the supernatant was used for DNA extraction. All DNA extractions were performed using the Qiagen QIAamp DNA mini kit (Thermo Fisher Scientific, NZ) and purified DNA was resuspended in $200 \mu \mathrm{L}$ of elution buffer (DEPC treated molecular grade water, LifeTechnology). DNA from sections of paraffin embedded tissues was extracted using the NucleoSpin FFPE DNA kit from Macherey-Nagel (Norrie Biotech, Auckland, NZ) and DNA was eluted in $20 \mu \mathrm{L}$ of DEPC water.

Subsequently, high throughput screening of nasal swab or blood in EDTA samples from multiple contacts of infected mares were performed with an automated KingFisher Flex Magnetic Particle Processor (Thermo Fisher Scientific, NZ) using a Macherey-Nagel NucleoMag VET kit (Norrie Biotech, Auckland, NZ)-and eluting DNA in $100 \mu \mathrm{L}$ of DEPC treated water. All kits were used according to the manufacturer's instructions and DNA was stored at $-20^{\circ} \mathrm{C}$ until ready for testing by qPCR. 


\section{Supplementary Information}

All qPCR was conducted using principles described by Bustin et al. (2010) and all PCR incorporated recommendations for diagnostic molecular testing by performing tests with positive and negative extraction controls, positive DNA controls and no DNA template controls using recommended procedures (OIE 2013). All samples were subjected to an 18S internal control qPCR using the TaqMan Ribosomal RNA kit (Applied Biosystems, Austin, Texas, USA) according to the manufacturer's instruction to confirm compatibility of the extracted DNA with efficient amplification. Samples from blood and tissue were also analysed using a Nanodrop ND8000 spectrophotometer to assess DNA concentration and quality by $\mathrm{A}_{260} / 280$ ratio. PCR for some samples was limited to $100 \mathrm{ng}$ of DNA per reaction to avoid amplification inhibition if determined by $18 \mathrm{~S}$ qPCR analysis. The presence of EHV-1 and EHV-4 DNA was screened by use of the EHV glycoprotein B TaqMan qPCR tests described by Diallo et al. (2006, 2007). Oligonucleotide primers and minor groove binding probes (MGB) were custom manufactured by Life Technologies. The EHV-1 qPCR used primers EHV-1 F1 (5'-CAT GTC AAC GCA CTC CCA-3') and EHV-1 R1 (5'-GGG TCG GGC GTT TCT GT-3') and the EHV-1 MGB probe (6FAM-CCC TAC GCT GCT CC-MGBNFQ) as described by Diallo et al. (2006, 2007). The EHV-4 qPCR used primers EHV-4 F1 (5'-GGGCTATTGGATTACAGCGAGAT-3') and EHV-4 R1 (5'-

TAGAATCGGAGGGCGTGAAG-3') and the EHV-4 MGB probe (VICCAGCGCCGTAACCAG-MGB-NFQ) (Diallo et al. 2007). Each test was performed as a singleplex reaction and consisted of $1 \mathrm{X}$ concentration of Platinum qPCR Supermix-UDG (Life Technologies, NZ), $5 \mathrm{pM}$ of each primer, $5 \mathrm{pM}$ of probe and up to $5 \mu \mathrm{L}$ of DNA (50-500 ng) in a 25 $\mu \mathrm{L}$ final volume. Quantitative PCR was performed in a 96-well plate format on a Bio-Rad CFX96 qPCR thermocycler (Bio-Rad Laboratories, Hercules, California, USA). The cycle threshold (Cq) values for all amplification plots were auto-calculated using the Bio-Rad CFX software. Samples producing a quantitative $\mathrm{Cq}$ less than 38 were reported as positive.

The performance of the EHV-1 qPCR assay has been described by Diallo et al. (2006) but we repeated performance testing of this assay to determine its suitability for diagnostic purposes. We performed analytical sensitivity testing of the EHV-1 qPCR by titration of tissue culture grown Durham strain virus (Hutton and Durham 1977) followed by DNA extraction and qPCR. The analytical sensitivity of the EHV-1 qPCR was 0.03 TCID $_{50}$ with a CV=0.0055. The accuracy of the EHV-1 qPCR had a CV=2.8\% and the repeatability by different operators had a CV=8.3\%. The analytical specificity was confirmed in house using DNA from tissue culture grown New Zealand field isolates of EHV-1, EHV-2, EHV-3 and EHV-4. We found there was a weak cross-reactivity between EHV-1 qPCR and EHV-4 DNA and likewise between EHV-4 qPCR and EHV-1 DNA from tissue culture grown high titre virus samples. Therefore both EHV-1 and EHV-4 qPCR assays 
were performed on diagnostic samples to confirm if a high Cq value (>30) in EHV-1 qPCR for example was not due to a high titre EHV-4 infection or vice versa.

All positive qPCR results were confirmed using conventional PCR tests targeting the thymidine kinase gene (Carvalho et al. 2000) and or the ORF30 gene (Nugent et al. 2006) using primers synthesised by Sigma. All conventional PCR was performed using Platinum Taq Supermix (Life Technologies) with $5 \mathrm{pM}$ of each primer and $5 \mu \mathrm{L}$ DNA in a $25 \mu \mathrm{L}$ final volume. The ORF30 PCR used primers 30-1s (5'-TAC CCA AGC ATT ATC CAG-3') and 30-1sr1 (5'-GAT AAC CCT GAC GGA GTA AG-3') (Nugent et al. 2006) with thermal cycling at $95^{\circ} \mathrm{C} 15 \mathrm{~min},\left[95^{\circ} \mathrm{C} 1 \mathrm{~min}, 60^{\circ} \mathrm{C} 1\right.$ $\min , 72^{\circ} \mathrm{C} 2 \mathrm{~min}$ ] for 40 cycles and $72^{\circ} \mathrm{C} 10 \mathrm{~min}$. ORF30 PCR amplicons were sequenced by a commercial laboratory (EcoGene, Auckland, NZ). DNA sequence analysis was performed using the Geneious software package version 7.1.5 (Biomatters, Auckland, NZ). Conventional PCR for EHV1 TK gene used oligonucleotide primers EH TK F1 (5'-CGG GAC CGC AGC TGG AAA T-3') and EH TK R2 (5'-CTG GCG AGA ACG CTA CCC-3') and for the EHV-4 strain used EH TK F5 (5'-TTG GGC CGT GGC CGA AAA C-3') and EH TK R6 (5'-CTA GCC AAA ACC TTG CCT$3^{\prime}$ ) as described by Carvalho et al. (2000) using the following thermal cycling program $95^{\circ} \mathrm{C}$ $15 \mathrm{~min},\left[95^{\circ} \mathrm{C} 20 \mathrm{~s}, 65^{\circ} \mathrm{C} 30 \mathrm{~s}, 72^{\circ} \mathrm{C} 30 \mathrm{~s}\right]$ for 35 cycles and $72^{\circ} \mathrm{C} 5 \mathrm{~min}$. All PCR products were separated by electrophoresis in tris-acetate EDTA buffer on 1.5\% agarose gels stained with Gel Red (Bio-Rad Laboratories), and bands were visualised by UV illumination.

\section{Virus culture}

Ten percent v/v blood in EDTA or nasal swabs in modified transport media and $10 \% \mathrm{w} / \mathrm{v}$ tissue sample homogenates were freeze-thawed once, centrifuged at $1350 \mathrm{x} g$ for 15 minutes and supernatants inoculated onto rabbit kidney (RK-13) or equine embryonic kidney (EEK) cells. One $\mathrm{mL}$ of supernatant was inoculated into a $25 \mathrm{~cm}^{2}$ flask or $50-200 \mu \mathrm{L}$ of supernatant was inoculated onto a single well of a 24 well plate seeded with cells at $3 \times 10^{5}$ cells/well. Cultures were incubated at $37^{\circ} \mathrm{C}$ in a $5 \% \mathrm{CO}_{2}$ incubator for seven days and monitored for cytopathic effect (CPE) by light microscopy. If no CPE was observed, cultures were freeze-thawed and passaged onto fresh cells for a second culture. DNA extracted from cell cultures that developed CPE was tested using the ORF30 PCR followed by DNA sequencing to confirm the isolation of EHV-1. 


\section{ELISA}

The SVANOVIR EHV-1/EHV-4 antibody discriminating test (Crabb et al. 1995) was performed according to the manufacturer's instructions (Svanova, Uppsala, Sweden). Sera were considered to be negative for EHV-1 antibody if the optical density (OD) at $450 \mathrm{~nm}$ of the test well was less than 0.1 , doubtful (suspicious) if $\mathrm{OD}_{450}$ was between 0.1 and 0.2 and positive if $\mathrm{OD}_{450}$ was higher than 0.2. Based on OD values for the positive control samples using non-normalised data, the $\mathrm{CV}$ for the EHV-1 ELISA was $37.9 \%$ and for the EHV-4 ELISA was $35.5 \%(n=75)$.

\section{Virus neutralization test}

Serum samples were heat inactivated at $56^{\circ} \mathrm{C}$ for 30 minutes and then subjected to a serial two-fold dilution in a 96 well cell culture microtitre plate and incubated with 100 TCID $_{50}$ of EHV-1 Durham strain at $37^{\circ} \mathrm{C}$ for 2 hours. Then $1.5 \times 10^{4} \mathrm{RK} 13$ cells were added to each well and plates were incubated at $37^{\circ} \mathrm{C}$ in $5 \% \mathrm{CO}_{2}$ for 3 days. Serum titres were determined from duplicate tests per sample (Thomson et al. 1976) and were expressed as the reciprocal of the highest serum dilution that inhibited development of CPE in 50\% of wells. The CV for the EHV VNT assay for the positive control virus titre was $19.7 \%(\mathrm{n}=41)$.

\section{References}

Carvalho R, Passos LMF, Martins S. Development of a differential multiplex PCR assay for equine herpesvirus 1 and 4 as a diagnostic tool. Journal of Veterinary Medicine Series B, 47, 351-9, 2000

Crabb BS, MacPherson CM, Reubel GH, Browning GF, Studdert MJ, Drummer HE. A type-specific serological test to distinguish antibodies to equine herpesviruses 4 and 1. Archives of Virology 140, 245-58,1995

Diallo IS, Hewitson G, Wright L, Rodwell BJ, Corney BG. Detection of equine herpesvirus type 1 using a real-time polymerase chain reaction. Journal of Virological Methods 131, 92-8, 2006

Diallo IS, Hewitson G, Wright LL, Kelly MA, Rodwell BJ, Corney BG. Multiplex real-time PCR for the detection and differentiation of equid herpesvirus $1(\mathrm{EHV}-1)$ and equid herpesvirus 4 (EHV-4). Veterinary Microbiology 123, 93-103, 2007

Hutton JB, Durham PJK. Equine herpesvirus type 1 (EHV-1) from aborted foals. New Zealand Veterinary Journal 25, 42, 1977

Nugent J, Birch-Machin I, Smith KC, Mumford JA, Swann Z, Newton JR, Bowden RJ, Allen GP, Davis-Poynter N. Analysis of equid herpesvirus 1 strain variation reveals a point mutation of the DNA polymerase strongly associated with neuropathogenic versus nonneuropathogenic disease outbreaks. Journal of Virology 80, 4047-60, 2006

OIE. OIE Manual for Terrestial Animals: Principles and methods of validation of diagnostic assays fof infectious disease (Chapter 1.1.5). http://www.oie.int/fileadmin/Home/eng/Health_standards/tahm/GUIDELINE_3.6.3_NAD_AS SAYS.pdf (accessed 5 March 2014), Paris, France, 2008

Thomson GR, Mumford JA, Campbell J, Griffiths L, Clapham P. Serological Detection of Equine Herpesvirus-1 Infections of the Respiratory Tract. Equine Veterinary Journal, 8, 58-65, 1976 
Supplementary Figure 1. Disease status and viral load of mares affected by equine herpesvirus myeloencephalopathy. The mares were contained within three areas; the newly affected area, the high risk area, comprising five paddocks (Pd) and the unaffected area. The day of outbreak indicated as ' $x$ ' days). $\Re=$ mares clinically affected; $M=$ mares clinically affected and euthanased; $\Re=$ mares not clinically affected but with laboratory evidence of previous exposure to equine herpesvirus type $1 ; M=$ mares with no evidence of recent exposure to the virus. The background colour of the paddocks indicates the virus load present based on testing blood in EDTA and nasal swabs from mares present in each paddock: $\square=$ virus detected by qPCR; $\square$ $=$ virus detected by qPCR but with a high $\mathrm{Cq}(\mathrm{Cq}>35)$ value or serological evidence that infection had been present; $\square=$ no virus detected or evidence of infection. Black arrows indicate where management interventions were made to move non-clinically affected virus negative (by qPCR) horses away from affected areas.

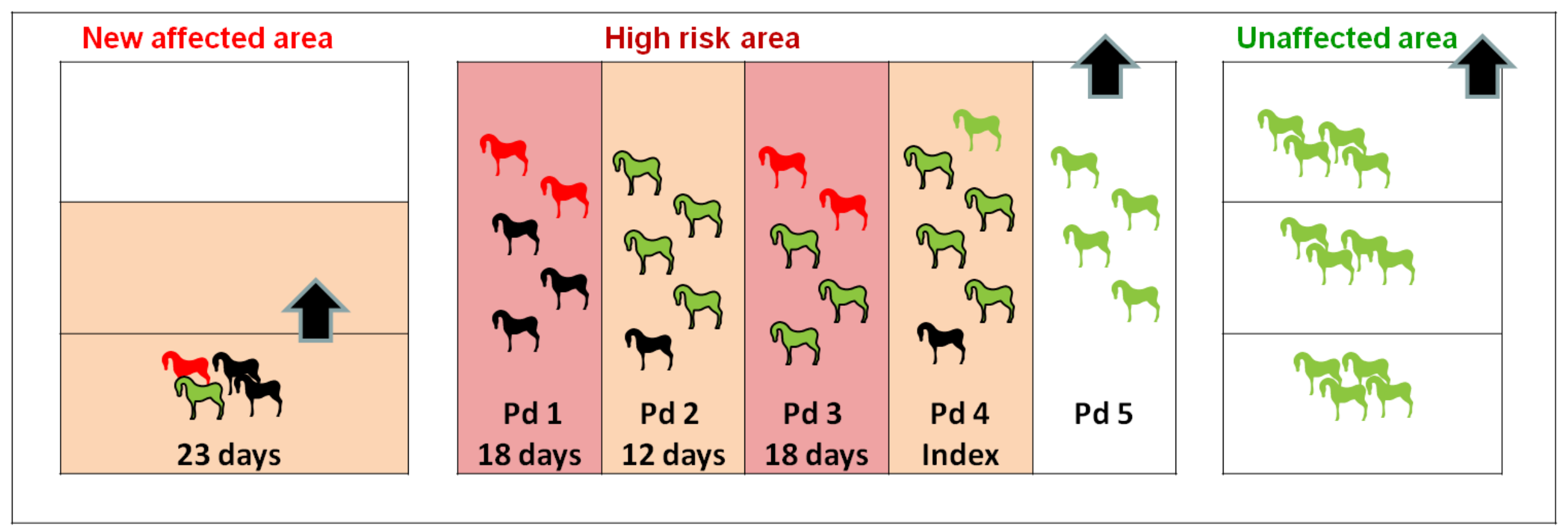

